East African Medical Journal Vol. 86 (Supplement) December 2009

RISK FACTORS FOR CARDIAC DYSFUNCTION IN CHILDREN ON TREATMENT FOR CANCER AT KENYATTA NATIONAL HOSPITAL, NAIROBI

M. Shiroya-Wandabwa, MBChB, MMed (Paed), International Centre for AIDS Programs, Kenya, C. Yuko-Jowi, MBChB, MMed (Paed), Senior Lecturer, R. Nduati, MBChB, MMed (Paed.), Associate Professor, Department of Paediatrics and Child Health, J. Githang'a, MBChB, MMed (Path), Senior Lecturer, Department of Human Pathology and D. Wamalwa, MBChB, MMed (Paed), Lecturer, Department of Paediatrics and Child Health, College of Health Sciences, University of Nairobi, P. O. Box 19676- 00202, Nairobi, Kenya

Requests for reprints to: Dr. M. Shiroya-Wandabwa, P. O. Box 29840-00202, Nairobi, Kenya

\title{
RISK FACTORS FOR CARDIAC DYSFUNCTION IN CHILDREN ON TREATMENT FOR CANCER AT KENYATTA NATIONAL HOSPITAL, NAIROBI
}

\author{
M. SHIROYA-WANDABWA, C. YUKO-JOWI, R. NDUATI, J. GITHANG'A and D. WAMALWA
}

\begin{abstract}
Objective: To determine the point prevalence of abnormal cardiac function and to assess the risk factors for cardiac dysfunction in paediatric oncology patients on treatment at Kenyatta National Hospital.

Design: Descriptive cross-sectional study with a nested case control.

Setting: Kenyatta National Hospital between February and April 2006.

Main outcome measures: Left ventricular dysfunction if ejection fraction (EF) $<55 \%$ or fractional shortening (FS) $<29 \%$ defined cases. Controls had EF $>55 \%$ or FS $>29 \%$.

Results: One hundred and eleven patients were enrolled of whom 32 had abnormal cardiac function and were classified as cases while 79 had normal cardiac function. About a third, point prevalence $29 \%$ (95\% CI 21.2-37.9), had cardiac dysfunction. Cumulative anthracycline dose was a risk factor for cardiac dysfunction in this population. Above $200 \mathrm{mg} / \mathrm{m}^{2}$ the attributable risk percentage of cardiac dysfunction was $77 \%$.

Conclusions: Serial echocardiography should be performed to identify patients at risk. Alternative treatment protocols should be used when the cumulative anthracycline dose exceeds $200 \mathrm{mg} / \mathrm{m}^{2}$ due to the high attributable risk. Studies to further assess the other associated risk factors and long term effects of anthracycline are recommended.
\end{abstract}

\section{INTRODUCTION}

It is estimated that the annual frequency of childhood cancers at Kenyatta National Hospital (KNH) is 125 cases per year. A review of some childhood cancers at KNH by Macharia (1), found the hospital based prevalence to be $1.27 \%$. The commonest childhood cancers were lymphomas (51\%), leukaemias $(22.3 \%)$, nephroblastoma $(8.5 \%)$, rhabdomyosarcoma $(5.3 \%)$, neuroblastoma $(3.3 \%)$, kaposi's sarcoma $(1.5 \%)$, ovarian cancers $(1.4 \%)$ and osteogenic sarcoma $(1.3 \%)$.

Cancer chemotherapeutic agents can be broadly classified as antibiotics, alkylating agents, antimetabolites, natural products and hormones agents (2). The two commonly used anthracycline antibiotics, daunorubicin and doxorubicin, differ only by one hydroxyl group in their biochemical structure. Doxorubicin is the main anthracycline used at Kenyatta National Hospital (KNH). Their anti-cancer activity is due to their ability to inhibit nucleic acid synthesis by binding to both parts of the deoxyribonucleic acid (DNA) helix thereby blocking the normal function of the ribonucleic acid (RNA) and DNA polymerase (3). Both the RNA and DNA undergo hepatic metabolism and biliary excretion. There is rapid uptake by the heart, lungs, kidney and spleen but they do not cross the blood brain barrier.

Anthracy cline antibiotics remain one of the most potent antineoplastic agents and have contributed enormously to the excellent treatment results seen in some childhood tumours worldwide (4). They, however, do have some unwanted systemic side effects. Anthracyclineeffects on the heart are probably the most well documented causes of morbidity and mortality in patients on anthracyclines. Early cardiotoxicity occurs during treatment or within a year of completion of treatment and can present as arrhythmias, ECG changes or left ventricular dysfunction. Late cardiotoxicity occurs more than a year after completion of treatment and presents as cardiomyopathy, pleural effusion, left ventricular dysfunction and low output heart failure. Early cardiotoxicity is a risk factor for late cardiotoxicity that is often not irreversible $(3,5,6)$. 
The mechanisms involved in anthracycline cardiotoxicity are not fully understood but are thought to include production of free radicals derived from the chemical reduction of anthracyclines through metabolic pathways catalyzed by iron, abnormalities in mitochondrial energy metabolism and intracellular calcium overload (3). The risk factors for cardiac dysfunction in children with malignancies are attributed to several factors:

The type of malignancy: Cancer contributes to cardiac dysfunction by several mechanisms, including tumour embolization leading to myocardial infarction, direct compression, nonbacterial thrombotic endocarditis by metastatic cancers or by extension into the great veins and cardiac chambers (7).

Radiotherapy: Early changes due to radiation include cytoplasmic damage, capillary injury, Von Willebrand factor release and acute inflammatory reaction. Chronic changes include cell death, fibroblastic proliferation, thickening of pericardium, valvular heart disease and arrhythmias (5). These changes often lead to a wide range of clinical sequelae including acute pericarditis, chronic pericarditis, coronary heart disease, myocarditis, valvular defects and conduction delays (8).

\section{Table 1}

The relative risk of cardiac toxicity at various anthracycline cumulative doses

\begin{tabular}{lc}
$\begin{array}{l}\text { Cumulative dose } \\
\left(\mathrm{mg} / \mathrm{m}^{2}\right)\end{array}$ & $\begin{array}{r}\text { Relative risk }(\%) \\
\text { for myocardial toxicity }\end{array}$ \\
\hline$<300 \mathrm{mg} / \mathrm{m}^{2}$ & $1-2 \%$ \\
$400 \mathrm{mg} / \mathrm{m}^{2}$ & $3-5 \%$ \\
$450 \mathrm{mg} / \mathrm{m}^{2}$ & $5-8 \%$ \\
$500 \mathrm{mg} / \mathrm{m}^{2}$ & $6-20 \%$ \\
\hline
\end{tabular}

Adapted from Taketomo, C.K., Hodding, J.H., Kraus, D.M. Paediatric Dosage Handbook, $13^{\text {th }}$ edn. New York: Lexi - Comp's Drug Reference Hand Book, 2006.

Cumulative anthracycline dose: The relative risk of cardiac toxicity increases with increasing anthracycline cumulative doses (9). Table 4 shows the relative risk of cardiotoxicity at various cumulative anthracycline doses.

Othercardiotoxic drugs: Cyclophosphamideis another potentially cardiotoxic drug which causes clinical cardiotoxicity when administered in massive doses (120 $-240 \mathrm{mg} / \mathrm{kg}$ over 1 to 4 days) (3).

Other additional factors associated withincreased occurrence of anthracycline cardiotoxicity are pre- existing cardiac disease, female sex, trisomy 21, black race, young age and nutritional status (6,9-13).

Various diagnostic procedures are used to test for anthracycline induced cardiotoxicity. These include history taking and physical examination, electrocardiography, echocardiography, angiography with radiolabeled antimyosin antibodies, angiocardiography and endomyocardial biopsy. Each with varying sensitivity and specificity.

Some of the strategies used to prevent or limit anthracycline cardiotoxicity include early detection followed by reductions in anthracycline dose or variation of treatment regime. Although serial echocardiography monitoring of left ventricular function will allow for early identification of individuals susceptible to cardiotoxicity and hence early intervention, increases in blood, troponin levels and myocardial uptake of radiolabeled antimyosin antibody are now emerging as the most sensitive and specific indicators of myocardial-cell injury (4, 7). Other strategies to limit or prevent anthracycline cardiotoxicity include lowering of peak blood levels by variations methods of delivery, for example, prolonged continuous infusion rather than by bolus injection; lowering of peak dose through the use of different treatment schedules or using alternative anthracycline derivatives, for example, liposomal anthracyclines, may be less cardiotoxic than other types of anthracyclines (3). Lipshultz et al (17) found dexrazoxane, a trial cardioprotective iron chelator, when given to children who were to receive doxorubicin was associated with reduction in myocardial injury as measures in terms of the troponin $\mathrm{T}$ level.

\section{MATERIALS AND METHODS}

This study was a descriptive cross-sectional study with a nested case control. It was carried out on patients admitted at the Kenyatta National Hospital $(\mathrm{KNH})$ paediatric oncology, general paediatric and ophthalmology wards. KNH is the teaching hospital for the University of Nairobi and is also the major referral hospital for all paediatric cancer patients in Kenya. The study population were children below the age of fifteen years with an established diagnosis of cancer and on chemotherapy. Patients whose parent or guardian did not give consent and re-admissions that had been recruited in the study in a previous admission were excluded from the study.

Fischer's formula was used to determine the minimum number of patients as 90 , taking into account the point prevalence of cardiac dysfunction. The sample size for the nested case control was determined by using the two sample comparisons of proportions for case control studies. A minimum number of thirty two cases were required taking a 
case: control ratio of 2:5, minimum number of cases was 32:79 (total 111 patients).

Prior diagnosis of cancer in the study group had been established using standard methods of bone marrow evaluation, fine needle aspirate, tissuebiopsy, biochemical markers depending on the type of cancer supported by various radiological investigations. This information was obtained from the patient's medical records. A patient history and general examination and was taken. Patient data including anthropometric measurements, cumulative anthracycline dose, cumulative cyclophosphamide dose and history of irradiation were collected.

Study patients underwent twelve lead surface electrocardiography (ECG) and rhythm strip using a manual cardiofax ECG machine, Nihon Kohden Corporation. 2-D echocardiography was also performed at the cardiology department using an echocardiographymachineLOGIQ500withfrequency of 33/02.5MH. The modalities of echocardiography used were two - dimensional real time, M-mode, pulsed wave dopppler and continuous wave Doppler echocardiography. 2D-real time echocardiography was used to assess the cardiac measurements, visual contractility and any abnormal findings like pericardial effusion, valvular abnormalities and cardiac masses. M-mode echocardiography was used to assess the relative chamber sizes and to calculate the indices of cardiac contractility. Spectral pulsed wave doppler with sample specimen taken at the tips of the mitral valve leaflets was used to assess diastolic function. Continuous wave doppler was used to assess the tricuspid regurgitation. Pulmonary pressures were derived from tricuspid regurgitation using the Bernoulli's equation, $\mathrm{P}=4 \mathrm{~V} 2$, where $\mathrm{P}$ is the pulmonary pressure and $\mathrm{V}$ is the maximum velocity of the tricuspid regurgitation gradient to estimate the pulmonary pressures.

To reduce interobserver errors M-mode echocardiography investigations were carried out separately by a team of three cardiologists using a uniform methodical protocol based on the set guidelines (8).

Data was analysed using SPSS (Statistical Packagefor SocialSciences software 11.0). Continuous variables were evaluated by $\mathrm{t}$-tests while Pearson chi - square tests were used to evaluate binary variables. Non-parametric test (Mann Whitney Test) was used to evaluate skewed continuous variables.

\section{RESULTS}

During the study period February and May 2006, a total of 111 children were evaluated. Their median age was six years (Range $0.25-14$ years) with $64 \%$ of them being males and $36 \%$ of them being females thus a male: female ratio of 1.8:1. Fifty four per cent of the study population were stunted with height/ age $Z$ score less than -2 , while $42 \%$ had less than $-2 \mathrm{Z}$ score weight /age. The median duration of chemotherapy treatment was four months (Range 0.25-24 months)

Lymphoma was the most common cancer - 31 $(27.5 \%)$ patients, followed by leukaemia and Wilm's tumour seen in $25(23 \%)$ and $22(20 \%)$ patients respectively. Other less common tumours were osteogenic sarcoma and neuroblastoma five (5\%) and four $(3.5 \%)$ patients respectively. Other rarer types included Kaposi's sarcoma, and ovarian tumours. Table 2 shows the spectrum of cancers seen in the study patients.

Of the 111 children enrolled 32 had abnormal cardiac function and were classified as cases. This gave a point prevalence of $29 \%(95 \%$ CI $21.2-37.9 \%)$. The other 79 children with normal cardiac function were the controls. The cumulative dose of adriamycin used at $\mathrm{KNH}$ varied according to the protocol used. Table 3 shows the various cumulative anthracycline doses set for each type of cancer depending on the regimen. The median dose of anthracycline was $128 \mathrm{mg} / \mathrm{m}^{2}\left(\right.$ Range $\left.0-500 \mathrm{mg} / \mathrm{m}^{2}\right)$ in cases and $88 \mathrm{mg} /$ $\mathrm{m}^{2}$ (Range $0-374 \mathrm{mg} / \mathrm{m}^{2}$ ) for controls as shown in Figure 1. The mean cumulative anthracycline dose was $176 \mathrm{mg} / \mathrm{m}^{2}\left(95 \%\right.$ CI $\left.117.5-211.4 \mathrm{mg} / \mathrm{m}^{2}\right)$ in the cases and $106 \mathrm{mg} / \mathrm{m}^{2}\left(95 \% \mathrm{CI} 84.1-129.9 \mathrm{mg} / \mathrm{m}^{2}\right)$ in the controls. This difference was statistically significant at $p=0.02$. Using percentiles it was shown that above a cumulative anthracycline dose of $201 \mathrm{mg} / \mathrm{m}^{2}$ there was a 4.4 increased odds of cardiac dysfunction with an attributable risk percentage of $77 \%$ (Table 4 ).

Table 2

The spectrum of cancers seen in 111 children

\begin{tabular}{llc}
\hline \multirow{2}{*}{ Type of cancer } & \multicolumn{2}{l}{ Patients } \\
& No. & $(\%)$ \\
\hline Lymphoma & & \\
$\quad$ Burkitt's lymphoma & 19 & 17 \\
Hodgkin's lymphoma & 8 & 7 \\
Non-Hodgkin's lymphoma & 4 & 3.5 \\
Leukaemia & 25 & 23 \\
Wilm's tumour & 22 & 20 \\
Rhabdomyosarcoma & 8 & 7 \\
Retinoblastoma & 7 & 6 \\
Osteogenic sarcoma & 5 & 5 \\
Neuroblastoma & 4 & 3.5 \\
Others & 9 & 8 \\
\hline Total & 111 & 100 \\
\hline
\end{tabular}


Table 3

The cumulative anthracycline doses for each cancer type according to treatment regimen at KNH

\begin{tabular}{lcc}
\hline Malignancy & $\begin{array}{c}\text { KNH regime } \\
1 \text { cumulative } \\
\text { dose }\end{array}$ & $\begin{array}{c}\text { KNH regime } \\
2 \text { cumulative } \\
\text { dose }\end{array}$ \\
\hline Leukaemia & 550 & 300 \\
Lymphomas & & 410 \\
NHL/BL & 440 & 360 \\
HL & 300 & 420 \\
Solid tumours & 360 & 80 \\
Wilm's tumour & 250 & \\
\hline
\end{tabular}

NHL $=$ Non Hodgkin's Lymphoma

$\mathrm{BL}=$ Burkitt's Lymphoma

Figure 1

Box plot showing the cumulative anthracycline dose in the study patients

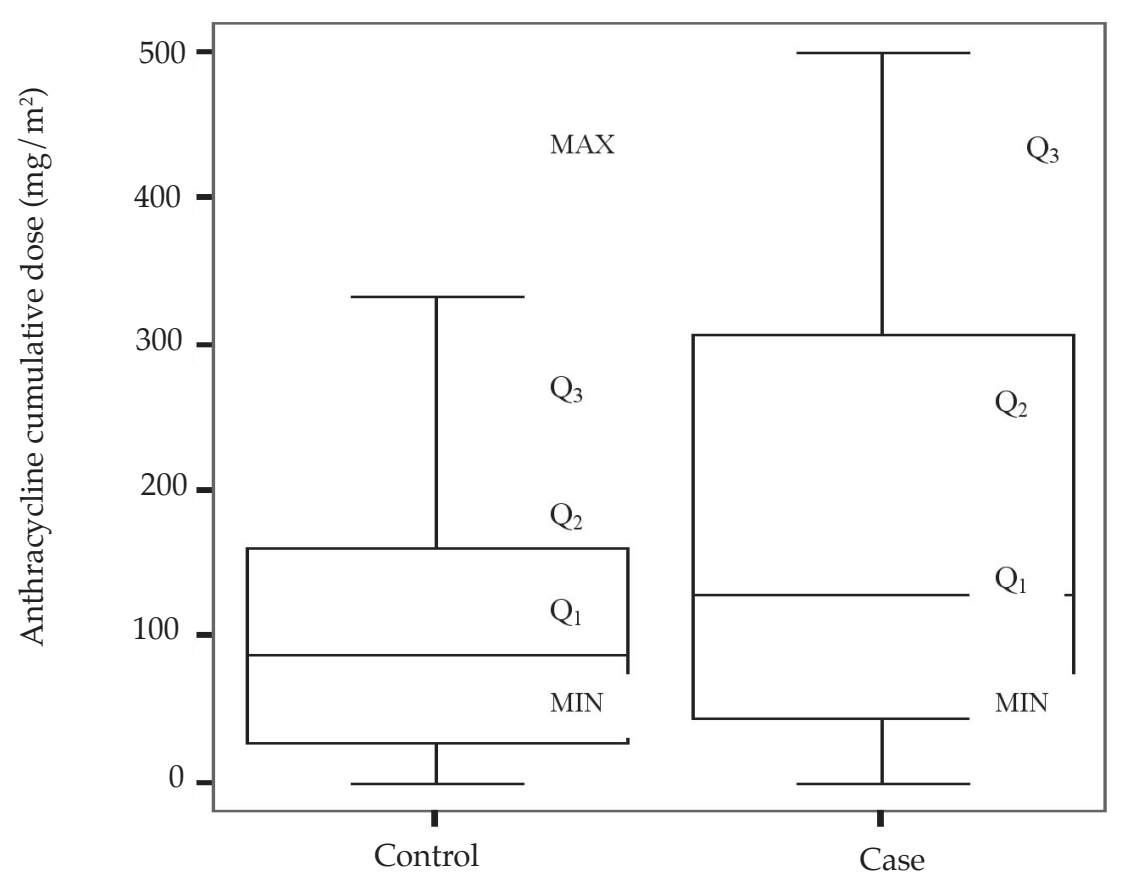

Key for controls:

Minimum dose $=0\left(\mathrm{mg} / \mathrm{m}^{2}\right)$

$25^{\text {th }}$ percentile $=28 \mathrm{mg} / \mathrm{m}^{2}$

$50^{\text {th }}$ percentile $=88 \mathrm{mg} / \mathrm{m}$

$75^{\text {th }}$ percentile $=160 \mathrm{mg} / \mathrm{m}^{2}$

Maximum dose $\left(\mathrm{mg} / \mathrm{m}^{2}\right)=374$
Key for case:

Minimum dose $\left(\mathrm{mg} / \mathrm{m}^{2}\right)=0$

$25^{\text {th }}$ percentile $=41 \mathrm{mg} / \mathrm{m}^{2}$

$50^{\text {th }}$ percentile $=128 \mathrm{mg} / \mathrm{m}^{2}$

$75^{\text {th }}$ percentile $=308 \mathrm{mg} / \mathrm{m}^{2}$

Maximum dose $\left(\mathrm{mg} / \mathrm{m}^{2}\right)=500$ 
Table 4

Summary of univariate analysis of categorical risk factors for cardiac dysfunction

\begin{tabular}{|c|c|c|c|c|c|c|}
\hline Variable & Category & No. & Case & $\begin{array}{l}\text { Control } \\
(\mathrm{n}=32)\end{array}$ & $\begin{array}{l}\text { Odd ratio } \\
(n=29)\end{array}$ & $\begin{array}{l}\text { P-value } \\
(95 \% \mathrm{CI})\end{array}$ \\
\hline \multirow[t]{2}{*}{ Sex } & Male & 71 & 22 & 49 & 0.7 & \\
\hline & Female & 40 & 10 & 30 & $(0.3-1.8)$ & 0.7 \\
\hline \multirow[t]{4}{*}{ Age } & $0-3.5$ & 25 & 8 & 17 & 1 & - \\
\hline & $3.6-7.5$ & 43 & 13 & 30 & $0.9(0.3-2.7)$ & 1.0 \\
\hline & $7.6-11.5$ & 33 & 9 & 24 & $0.8(0.3-2.9)$ & 0.8 \\
\hline & $11.6-77.5$ & 10 & 2 & 8 & $0.5(0.1-3.1)$ & 0.7 \\
\hline Nutritional status & $\leq 2$ & 60 & 17 & 43 & $1(0.5-2.5)$ & 1.0 \\
\hline Weight/Age & $\geq 2$ & 47 & 14 & 33 & & \\
\hline Nutritional status & $\leq 2$ & 51 & 16 & 35 & $0.8(0.4-1.8)$ & 0.7 \\
\hline Height/Age & $\geq 2$ & 60 & 16 & 44 & & \\
\hline \multirow[t]{4}{*}{ Type of cancer } & Leukaemia & 25 & 9 & 16 & 1 & - \\
\hline & Lymphoma & 31 & 10 & 21 & $0.8(0.3-2.6)$ & 0.8 \\
\hline & Nephroblastoma & 22 & 5 & 17 & $0.5(0.1-1.9)$ & 0.4 \\
\hline & Other solid tumours & 33 & 8 & 25 & $0.6(0.2-1.8)$ & 0.4 \\
\hline \multirow{5}{*}{$\begin{array}{l}\text { Anthracyclines } \\
\text { Cumulative dose } \\
\left(\mathrm{mg} / \mathrm{m}^{2}\right)\end{array}$} & & & & & & \\
\hline & $0-30$ (up to $25^{\text {th }}$ percentile) & 29 & 5 & 24 & 1 & - \\
\hline & $30.1-94$ (up to $50^{\text {th }}$ percentile) & 26 & 9 & 17 & $2.5(0.7-8.9)$ & 0.2 \\
\hline & $94.1-201$ (up to $75^{\text {th }}$ percentile) & 30 & 6 & 24 & $1.2(0.3-4.5)$ & 1.0 \\
\hline & $>201\left(>75^{\text {th }}\right.$ percentile $)$ & 25 & 12 & 13 & $4.4(1.3-15.4)$ & 0.02 \\
\hline
\end{tabular}

The median cumulativecyclophosphamidedose was $2050 \mathrm{mg} / \mathrm{m}^{2}$ (Range $\left.0-9363 \mathrm{mg} / \mathrm{m}^{2}\right)$ for cases and $1510 \mathrm{mg} / \mathrm{m}^{2}\left(0-10300 \mathrm{mg} / \mathrm{m}^{2}\right)$ for controls. The mean cumulative cyclophosphamide dose was $2880 \mathrm{mg} / \mathrm{m}^{2}$ $\left(95 \%\right.$ CI $\left.1804.0-3515.2 \mathrm{mg} / \mathrm{m}^{2}\right)$ in the cases and 2248 $\mathrm{mg} / \mathrm{m}^{2}\left(95 \%\right.$ CI $\left.1758.2-2874.9 \mathrm{mg} / \mathrm{m}^{2}\right)$ in the controls. This difference was not significantly associated with cardiac dysfunction at $\mathrm{p}=0.3$ (Table 5).

There was no association found between sex or nutritional status (Weight/ Age or Height/Age) and the frequency of cardiac dysfunction. Using the youngest age category as a reference, no association between age and cardiac dysfunction was seen. Using patients with leukaemia as the comparison group, no difference in risk for cardiac dysfunction by malignancy type was observed.

\section{DISCUSSION}

This study found that the commonest type of cancer seen were the lymphomas $(28 \%)$. This figure was less than that found in the study by Macharia (1) which found lymphomas to be $51 \%$. The latter study however, did not look at retinoblastoma and brain tumours which are relatively common cancers in childhood. Both studies found Burkitt's lymphoma to be the most common lymphoma making up about 2/3 of the lymphoma cases. Nephroblastoma was also more frequent in our study.

Childhood cancers continue to be an important area in paediatrics. The harmful side effects of the various chemotherapeutic agents versus their useful anticancer effects present patient management challenges. In long-term survivors, the possible late effects of treatment and their consequences for the quality of life are a major concern.

In this study left ventricular function was evaluated in a total of 111 paediatric cancer patients. The point prevalence for cardiac dysfunction in children on treatment for cancer was $29 \%$ (95\% CI 21.5-37.9). This represents about a third of the patients on treatment and is at a higher frequency than previously described $(3,7)$. The risk of cardiac dysfunction or cardiotoxiticy as measured by left ventricular dysfunction was related to cumulative anthracycline dose. The median duration of therapy of four months is an indication of early phase of treatment; hence the cardiac dysfunction seen was a measure of early anthracycline cardiotoxicity. In this study, there was a 4.4 odds of cardiotoxicity above 
a cumulative dose of $200 \mathrm{mg} / \mathrm{m}^{2}$ (Relative Risk 4.4, 95\% CI 1.3-15.4, $\mathrm{p}$-value $=0.02)$. Previous studies, mainly in developed countries, have documented the relative risk of cardiotoxicity at cumulative dose $<300 \mathrm{mg} / \mathrm{m}^{2}$ to be between $1-2 \%$ (14). This suggests increased susceptibility amongst our population. It is worth noting that black race has been noted to be a risk factor for anthracycline cardiotoxicity. This maybe due to perhaps race related differential pharmacogenomics.

Asshown in other studies, young age at diagnosis is one of the strongest predictors of a thin left ventricular wall, which leads to an elevated afterload in patients treated with anthracyclines $(3,6)$. Although this study did not clearly show age to be a risk factor, in the categorical analysis for age, the Odds ratio for cardiac dysfunction appeared to be reducing with increasing age suggesting that young age may be a risk factor for cardiac dysfunction in children on treatment for cancer. The linear tend for $p$-value was however not significant. The small number of subjects analysed may have been the limiting factor.

Based on the study findings, we advocate routine serial echocardiography to identify at risk patients. Where there is a cumulative anthracycline dose of $200 \mathrm{mg} / \mathrm{m}^{2}$, use of alternative treatment protocols, or reduction of the anthracycline dose is suggested. Variations of the method of delivery, use of liposomal anthracycline, where feasible, are other strategies that may be tried. Studies to further assess other risk factors associated with cardiotoxicity and the long term effects of anthracyclines are recommended.

\section{ACKNOWLEDGEMENTS}

To the Kenyatta National Hospital for permission to perform the study; the paediatric oncology, ophthalmology and general paediatric wards; the heart unit; and last but not least the patients and their parents/guardians.

\section{REFERENCES}

1. Macharia, W.M. Childhood cancers in a referral hospital in Kenya: A Review. East Afr. Med. J. 1996; 73: $647-650$.

2. Bennett, P.N. and Brown, M.J. Clinical Pharmacology, $9^{\text {th }}$ edn. New York: Churchill Livingston Publishers, 2003: $605-607$.
3. Ferrari, R., Opasich, C. and Tarazzi, L. Heart Failure 181 Questions \& Answers. New York: Medical Publishing Division, 2003.

4. Kermer, L.C.M. and Huib, N.C. Anthracycline cardiotoxicity in children. New Eng. J. Med. 1999; 352: $120-121$.

5. Braunwald. Heart Disease: A Textbook of CVS Medicine $4^{\text {th }}$ edn. New Haven: Saunders Company, 2004; 57: $1754-1760$.

6. Grenier, M.A. and Lipshultz, S.E. Epidemiology of anthracycline cardiotoxicity in children and adults. Semin. Oncol. 1998; 25: 72 - 85.

7. Bu'llock, F.A., Mott, M.G., et al. Early identification of anthracycline cardiomyopathy: Possibilities and implications. Archives Dis. Child. 1996; 75: 416-422.

8. Henry, W.L., De Maria, A., Gramiak, R., et al. Report of the American Society of Echocardiography Committee on Nomenclature and Standards in two - dimensional echocardiography. J. Am. Coll. Cardiol. 1983; 6: $1471-1478$.

9. Taketomo, C.K., Hodding, J.H. and Kraus, D.M. Paediatric Dosage Handbook, $13^{\text {th }}$ edn. New York: Lexi - Comp's Drug Reference Hand Book, 2006.

10. Garson, A.J., Bricker, J.T., Fisher, D. J., et al. The Science and Practice of Pediatric Cardiology. $2^{\text {nd }}$ Edition. Lippincott Williams and Wilkins. 1990; 2: $2337-2349$

11. Cameron, E.H., Lipshultz, S.E., Tarbell, N.J., et al. Cardiovascular disease in long - term survivors of pediatric hodgkin's disease. Progress Pediatr. Cardiol. 1998; 8: 139-144.

12. Von Hoff, D.D., Layard, M.W., Basa, P., et al. Daunomycin - induced cardiotoxicity in children and adults: A Review of 110 cases . Am. J. Med. 1977; 62: $200-207$.

13. Lipshultz, S.E., Lipsitz, S.R., Sallan, S.E., et al. Female sex and high drug dose as risk factors for late cardiotoxic effects of doxorubicin therapy for childhood cancers. New Eng. J. Med. 332: 1738- 1744

14. Krischer, J.P., Epsteins, S., Cuthbertson, P.D., et al. Clinical cardiotoxicity following anthracycline treatment for childhood cancer: The pediatric oncology group experience. J. Clin. Oncol. 1997; 15:1544-1552.

15. Von Hoff, D.D., Layard, M. and Basa, P. Risk factors for doxorubicin induced congestive heart failure. Ann. Intern. Med. 1979; 91: $710-717$.

16. Mohta, R., Saxena, A., Jain, Y., et al. Anthracycline associated cardiac toxicity in children with malignancies. Indian Pediatrics. 2002; 39: 549 - 555.

17. Lipshultz, S.E., Rifai, N., Dalton, V.M., et al. The effect of dexrazone on myocardial injury in doxorubicin -treated children with acutelymphoblasticleukaemia. New Eng. J. Med. 2004; 351: 145-153. 